\section{Pediatric Neuromyelitis Optica Spectrum Disorder and Sjögren Syndrome: More Common Than Previously Thought?}

\section{To the Editor:}

We read with interest the report by Kornitzer, et al ${ }^{1}$ in The Journal and agree that increased awareness and a better understanding of the association between pediatric systemic autoimmunity and neuromyelitis optica spectrum disorder (NMOSD) is warranted. In their report, Kornitzer, et al refer to cases previously published by our group as unconfirmed cases of NMOSD because of a lack of NMO immunoglobulin $\mathrm{G}(\mathrm{IgG})$ results $^{1}$. Here, we provide additional information regarding these cases, as well as 2 new cases to highlight the co-occurrence of childhood Sjögren syndrome (SS) and NMOSD.

The Institutional Review Board approved this study. A waiver of consent/assent was obtained.

Case 1 was an 11-year-old African American girl initially hospitalized for acute transverse myelitis and bilateral optic neuritis in the setting of sicca symptoms. Antinuclear antibody (ANA), SSA, and SSB antibodies were positive. Lip biopsy was consistent with SS (Table 1). Because the patient was diagnosed in 2003, 1 year prior to the discovery of the aquaporin-4 antibody ${ }^{2}$, NMO-IgG testing was unavailable. She was readmitted 5 years later with jerking upper extremity movements and altered cognitive speed. Brain magnetic resonance imaging (MRI) revealed interval progression of disease with an enlarged expansile $\mathrm{T} 2$ hyperintense lesion extending from T3-T5. Serum NMO-IgG testing was positive. She was treated with intravenous methylprednisolone, rituximab (RTX), cyclophosphamide (CYC), and apheresis. Initial report of this case $^{3}$ was prior to her subsequent NMO-IgG testing, and details of her positive NMO-IgG status were not included in subsequent studies that were focused more on childhood SS than on $\mathrm{NMOSD}^{4,5}$. Thus, case 1 clearly meets diagnostic criteria for $\mathrm{NMOSD}^{6}$.

Case 2 is a 13-year-old African American girl diagnosed with concomitant SS and NMOSD after presenting with acute visual changes because of left optic neuritis. This case was previously reported in research focused on childhood SS and therefore did not include full details regarding her neurologic course ${ }^{4,5}$, which we outline here. She developed blurry vision in her left eye accompanied by pain with left lateral gaze and supraorbital headache. Vision improved after 3 days of methylprednisolone. MRI of the brain and spine showed hyperintensities in the posterior internal capsules on fluid attenuation inversion recovery images. MRI of the cervical and thoracic spine showed expansion and $\mathrm{T} 2$ prolongation with a patchy lesion involving the cervical and thoracic spine. Spinal fluid examination showed white blood cell count $600 \mathrm{u} / 1$ with $59 \%$ lymphocytes, red blood cell count $370 \mathrm{u} / \mathrm{l}$, glucose of $51 \mathrm{mg} / \mathrm{dl}$, and protein of $220 \mathrm{mg} / \mathrm{dl}$. Cerebrospinal antineuronal antibodies were negative and serum NMO-IgG was positive. She had a high-titer ANA and positive SSA and SSB antibodies, along with a lip biopsy demonstrating histopathology characteristic of SS (Table 1). She was initially treated with hydroxychloroquine, glucocorticoids, and CYC, and transitioned to mycophenolate; however, owing to worsening visual symptoms, she received apheresis and RTX.

To identify additional cases of NMOSD and SS, we performed a retrospective chart review at The Children's Hospital of Philadelphia, Pennsylvania, USA, from May 1, 2001, until January 1, 2016. All patients with the International Classification of Diseases-9-Clinical Modification code for NMO were included. In addition to the 2 aforementioned cases, we identified an additional 2 children with NMOSD who were diagnosed with SS by a pediatric rheumatologist. Case 3 was a 15-year-old African American boy with a history of autism with intractable emesis and hiccups that resolved after empiric treatment with methylprednisolone. He was found to have positive NMO-IgG and demyelinating brain and spinal lesions along with positive ANA, SSA, SSB, and RNP antibodies (Table 1). A lip biopsy was deferred given need for general anesthesia. He was initiated on mycophenolate and RTX for NMOSD and probable SS.

Case 4 was an 11-year-old white boy with a history of encephalitis presenting with blurry vision. NMO-IgG was positive and imaging demonstrated left optic nerve enhancement resulting in a diagnosis of NMOSD. He had positive SSA and ANA antibodies. He had sicca symptoms and mildly reduced salivary pooling. Salivary gland cysts were visualized on ultrasound and a lip biopsy demonstrated chronic sialadenitis and focus score $>0$ foci $/ 4 \mathrm{~mm}^{24}$.

These 4 cases demonstrate the common autoimmune milieu shared between pediatric NMOSD and $\mathrm{SS}^{7,8}$. Three of the 4 cases had confirmatory lip biopsy results for SS that Kornitzer, et al cite as a distinguishing feature of their case report. However, all our NMOSD cases had positive SSA antibodies highlighting the relationship between NMOSD and SS. Given the lack of validated diagnostic or classification criteria for pediatric $\mathrm{SS}^{9,10}$, further elucidation of the association between NMOSD and SS may inform future diagnostic criteria for SS. The presence of anti-SSA or SSB antibodies in a child with NMOSD should prompt further evaluation for SS including a biopsy and/or imaging studies to assess for salivary or lacrimal gland inflammation. Similarly, neurologic involvement in pediatric SS should prompt an evaluation for NMOSD.

Table 1. Cases of pediatric NMO spectrum disorder and confirmed or probable SS.

\begin{tabular}{|c|c|c|c|c|c|c|c|c|c|c|}
\hline$\# 1$ & Confirmed & $\begin{array}{l}\text { African } \\
\text { American }\end{array}$ & 11 & F & 108.7 & 35.5 & $1: 160$ & Positive & $\begin{array}{l}\text { Aggregates of minor salivary glands with } \\
\text { several foci of periductal primarily lymphocytic } \\
\text { inflammation consistent with SS. }\end{array}$ & $\begin{array}{l}\text { Positive } \\
\text { Schirmer } \\
\text { test }\end{array}$ \\
\hline$\# 2$ & Confirmed & $\begin{array}{c}\text { African } \\
\text { American }\end{array}$ & 13 & F & 108.9 & 76.7 & $\geq 1: 1280$ & Positive & $\begin{array}{l}\text { Multiple sections show regional mucous } \\
\text { gland lobules exhibiting multiple discrete foci } \\
\text { of lymphocytes and plasma cells consistent with SS. }\end{array}$ & $\begin{array}{l}\text { Normal } \\
\text { Schirmer } \\
\text { test }\end{array}$ \\
\hline$\# 4$ & Confirmed & White & 11 & M & 158.3 & Negative & $1: 160$ & Positive & $\begin{array}{l}\text { Multiple sections show regional } \\
\text { mucous gland lobules exhibiting duct ectasia, } \\
\text { acinar degeneration, stromal fibrosis, and an } \\
\text { infiltrate of lymphocytes and plasma cells, } \\
\text { and focus score }>0 \text { foci } / 4 \mathrm{~mm}^{2} \text {. }\end{array}$ & $\begin{array}{l}\text { Reduced } \\
\text { salivary pooling. } \\
\text { Salivary gland } \\
\text { cysts visualized } \\
\text { on ultrasound. }\end{array}$ \\
\hline
\end{tabular}

* Normal range for anti-SSA, anti-SSB, and anti-RNP antibodies based on ELISA testing: 0-19 units. ${ }^{\dagger}$ ANA titer reference range by immunofluorescence testing: 1:20. NMO: neuromyelitis optica; SS: Sjögren syndrome; ANA: antinuclear antibody; IgG: immunoglobulin G.

Personal non-commercial use only. The Journal of Rheumatology Copyright $(\subset) 2017$. All rights reserved. 
SABRINA GMUCA, MD, Department of Pediatrics, Division of Rheumatology, The Children's Hospital of Philadelphia, Philadelphia, Pennsylvania; SCOTT M. LIEBERMAN, MD, PhD, Stead Family Department of Pediatrics, Division of Rheumatology, Carver College of Medicine, University of Iowa, Iowa City, Iowa; JAY MEHTA, MD, MS, Department of Pediatrics, Division of Rheumatology, The Children's Hospital of Philadelphia, Philadelphia, Pennsylvania, USA. Dr. Gmuca is supported by the US National Institutes of Health Rheumatology Research Training Grant T32-AR007442-29. Address correspondence to Dr. S. Gmuca, Department of Pediatric Rheumatology, The Children's Hospital of Philadelphia, 34th Street and Civic Center Boulevard, Wood Building, Fourth Floor, Philadelphia, Pennsylvania 19104, USA.

E-mail: gmucas@email.chop.edu

\section{REFERENCES}

1. Kornitzer JM, Kimura Y, Janow GL. Primary Sjögren syndrome in a child with a neuromyelitis optica spectrum disorder. J Rheumatol 2016;43:1260-1.

2. Lennon VA, Wingerchuk DM, Kryzer TJ, Pittock SJ, Lucchinetti $\mathrm{CF}$, Fujihara K, et al. A serum autoantibody marker of neuromyelitis optica: distinction from multiple sclerosis. Lancet 2004;364:2106-12.

3. Arabshahi B, Pollock AN, Sherry DD, Albert DA, Kreiger PA, Pessler F. Devic disease in a child with primary Sjogren syndrome. J Child Neurol 2006;21:285-6.

4. Yokogawa N, Lieberman SM, Alawi F, Bout-Tabaku S, Guttenberg M, Sherry DD, et al. Comparison of labial minor salivary gland biopsies from childhood Sjögren syndrome and age-matched controls. J Rheumatol 2014;41:1178-82.

5. Yokogawa N, Lieberman SM, Sherry DD, Vivino FB. Features of childhood Sjogren's syndrome in comparison to adult Sjogren's syndrome: considerations in establishing child-specific diagnostic criteria. Clin Exp Rheumatol 2016;34:343-51.

6. Wingerchuk DM, Banwell B, Bennett JL, Cabre P, Carroll W, Chitnis T, et al; International Panel for NMO Diagnosis. International consensus diagnostic criteria for neuromyelitis optica spectrum disorders. Neurology 2015;85:177-89.

7. Carvalho DC, Tironi TS, Freitas DS, Kleinpaul R, Talim NC, Lana-Peixoto MA. Sjogren syndrome and neuromyelitis optica spectrum disorder co-exist in a common autoimmune milieu. Arq Neuropsiquiatr 2014;72:619-24.

8. Wingerchuk DM, Weinshenker BG. The emerging relationship between neuromyelitis optica and systemic rheumatologic autoimmune disease. Mult Scler 2012;18:5-10.

9. Houghton K, Malleson P, Cabral D, Petty R, Tucker L. Primary Sjögren's syndrome in children and adolescents: are proposed diagnostic criteria applicable? J Rheumatol 2005;32:2225-32.

10. Bartůnková J, Sedivá A, Vencovský J, Tesar V. Primary Sjogren’s syndrome in children and adolescents: proposal for diagnostic criteria. Clin Exp Rheumatol 1999;17:381-6.

J Rheumatol 2017;44:6; doi:10.3899/jrheum.160978 